\title{
Research on Selection of Technological Innovation Mode for Large and Medium-Sized Construction Enterprises in China
}

\author{
Jianwen Wang, Yunbo Ye \\ School of Management and Economics, Southwest Jiaotong University, Chengdu, China \\ Email: tmlbt1978@163.com
}

How to cite this paper: Wang, J.W. and Ye, Y.B. (2017) Research on Selection of Technological Innovation Mode for Large and Medium-Sized Construction Enterprises in China. Technology and Investment, 8, 131-141.

https://doi.org/10.4236/ti.2017.82011

Received: April 14, 2017

Accepted: May 24, 2017

Published: May 27, 2017

Copyright (c) 2017 by authors and Scientific Research Publishing Inc. This work is licensed under the Creative Commons Attribution International License (CC BY 4.0).

http://creativecommons.org/licenses/by/4.0/

\begin{abstract}
Strengthening Technological Innovation is the Fundamental Way to Strengthen Core Competitiveness of Large and Medium Construction Enterprises in China and Realize Sustainable Development. The construction of a technological innovation model that conforms to the enterprise's own conditions is an important premise to effectively integrate the internal and external innovation resources, reduce the cost and risk of innovation and improve the innovation performance. In this paper, the technology innovation model of large and medium-sized construction enterprises is divided into an independent innovation model, imitating innovation mode and cooperative innovation mode. Through the establishment of three-dimensional model, this paper aims to provide a quantitative analysis method for large and medium-sized construction enterprises in China.
\end{abstract}

\section{Keywords}

Core Competencies, Sustainable Development, Technology Innovation Model, Three-Dimensional Model

\section{Introduction}

Due to the increasingly competition in the market, companies around the world have taken the technical innovation as a key way beyond their rivals. Many factors will influence on the enterprise innovation ability and performance, but some research suggests that the choice of enterprise technology innovation mode is a key factor influencing the performance of innovation. For example, Chen Y. M. [1] points out that under the condition of market economy, the success of technology innovation is closely related to the selection of technological innovation mode. Zhong J. W. [2] [3] [4] think that how to choose the enterprise 
technology innovation mode is the key problem to enhance the core competitiveness of enterprises. Han $\mathrm{Zh}$. [5] think that the essence of technology innovation model is a kind of way to integrate the enterprise' internal and external innovation resources, through this integration, the enterprise technology innovation ability will enhance.

Construction industry is the important pillar industry in China. According to the latest figures provided by the Chinese National Bureau of Statistics, in 2016, the construction industry output in China arrived at 19.3657 trillion yuan which was as high as $26 \%$ of the GDP in China. Meanwhile, the number of construction workers was 50.034 million. Although China's construction industry has made great progress, the high-speed growth in the past, to a great extent, is based on the expansion of quantity rather than quality and $t$ efficiency. The contribution rate of scientific and technological progress to construction is only $20 \%$ $30 \%$ which is far away from $70 \%-80 \%$ at which many developed countries have arrived. The labor productivity in China is only $30 \%-40 \%$ of developed countries such as Europe and the United States [6]. The technology innovation model of most domestic large and medium-sized construction enterprise is inefficient and unsustainable.

Many scholars explored the enterprise technology innovation mode in a different perspective. Fu J. J. [7] believed that the purpose of selecting technological innovation mode was to effectively integrate resources and achieve the optimal configuration of innovation resources. An Y. N. [8] studied the technology innovation mode for large enterprise and thought that with the expansion of enterprise scale and the ascension of technical level, the path from the external innovation mode to cooperative innovation mode, then to independent innovation mode, was the main innovation mode choice enterprise adopted. Chen Y. X. [9], according to the technical ability theory, think that with the enhancement of technical ability, the evolution of technological innovation mode of trajectory should be gradually from imitation innovation to cooperative innovation and independent innovation. Guo Ch. D. [10], in view of the theory of technical innovation power factor, put forward the model of technology innovation and a quantitative model for path selection. Zeng H. [11], from the perspective of social capital, put forward the technology innovation strategy alliance and virtual organization mode for construction companies.

The above shows that the research on enterprise technology innovation mode selection has made some achievements, but there is still some deficiency. Previous research is often based on the enterprise internal and external environment [1] [2], as well as a single dimension such as technical ability [8] [9], and the study on multiple dimensions of enterprise technology innovation mode is less. Meanwhile, many researchers focus on the qualitative analysis and the quantitative analysis is less. Most of the research on construction technology innovation only focus on the industry level and is short of microscopic research on technical innovation mode and selection [12]. Because the large and medium-sized construction enterprise is the main force of China's construction 
industry innovation, this paper intends to establish a three-dimensional model to choose the technological innovation model and provide a quantitative method for such enterprises.

\section{Technological Innovation Mode Selection Index System for Large and Medium-Sized Construction Enterprises}

\subsection{The Classification of the Enterprise Technology Innovation Mode for Large and Medium-Sized Construction Enterprises}

Wang B. Y. [12] believe that technology innovation model is the combination and configuration of many different factors in the innovation process, which is combined related to technical production, selection, organization, application and diffusion method. Chen Y. M. [13] and Xia, C.Y. [14] put forward that the so-called technical innovation mode refers to a way of resource allocation related to technical source, selection, organizational management and application.

Many scholars summarized the type of enterprise technology innovation mode. Tang Q. Q. [15] divided the enterprise technology innovation model into exploratory innovation and use innovation. Wang H. G. [16] divided the enterprise technology innovation model into technology-driving model, demanddriving model, and combination-driving mode. Gao N. N. [17] according to the main body and the impetus of innovation, classify the construction enterprise technology innovation mode. The former includes the independent innovation, imitating innovation and cooperative innovation and the latter including linear mode, interactive mode and circular patterns.

This paper argues that the enterprise technology innovation mode, in the general sense, is the set of methods or strategies which select reasonable form of technological innovation to effectively integrate internal and external innovation resources and maximize the benefit of the technology innovation. Fu J. J. divided the technological innovation mode into three patterns such as independent innovation, imitation innovation, and cooperative innovation. This classification is generally accepted for most researchers [8] [11] [17] [18] [19] [20], so this article continues to follow it. Furthermore, we will divide the technology innovation model for large and medium-sized construction enterprise into the following six kinds:

1) Independent innovation (F1)

Independent innovation is the technology innovation activities by enterprise itself and based on the research and development ability of enterprise itself. Independent innovation mode needs the enterprise has strong R\&D strength and the accumulation of research results, and the enterprise is at the technical leading status. This pattern is generally applicable to big companies such as Microsoft, Dupont etc. For the construction industry, independent technological innovation ability is the fundamental guarantee of its survival and development. This article will divide the enterprise independent innovation model into three basic patterns such as original innovation, integrated innovation, introduction and absorption innovation. 
2) Integrated innovation mode (F2)

Integrated innovation model is an independent innovation model based on the integrated innovation elements. In this model, enterprise according to the potential market demand and the characteristics of their own innovation elements such as strategy, technology, knowledge and organization, etc., initiatively adopt the system engineering theory and method to select, optimize and integrate enterprise' various internal and external innovative elements and the make these elements aggregate organically [19]. With the rapidly development of science and technology and changing market demand, technical integrated innovation can promote the scientific and technological achievements transformed into advanced productivity.

3) Innovation model via introduction, digestion and absorption (F3)

Innovation model via introduction, digestion and absorption is an effective model which can make enterprise shorten the technology gap relative to other advanced enterprises. Based on introduction, digestion and absorption of advanced technology, enterprise can improve their technical level and gradually accumulate their own technical strength and experience in order to take the secondary innovation to seek greater market. This model is suitable for enterprise technological infancy. At present, overall technical innovation ability of Chinese large and medium-sized construction enterprises is not strong, therefore, closing the gap by introducing more innovation, enhance the capacity of technology innovation, It is indispensable for them to take this model to enhance their competitiveness.

4) Imitation innovation (F4)

Imitation innovation is that the enterprise imitation the technical achievements and the operation mode which some enterprise firstly have conducted, and on this basis, the enterprise make different degrees of improvement and creation and provide the market with similar technology product to obtain profits. Because the imitation innovation enterprise does not have technology leading position, so when a new round of technological innovation summit comes, they are easy in passive situation. Imitation innovation is characterized by low investment, low risk and strong adaptability to the market. Hence, Imitation innovation is generally used by many enterprises such as Panasonic and Sanyo Electric.

5) Cooperative innovation (F5)

Cooperative innovation refers to the technology innovation cooperated by two or more enterprises or institutions under their technology. [17] Cooperative innovation is a kind of technological innovation mode including resource sharing, complementary advantages of technological and is characterized by the resource sharing, risk-sharing, cooperation and long cooperation cycle, etc.

6) Industry-university-research cooperation innovation mode (F6)

Industry-university-research cooperation innovation mode refers to enterprises, universities and research institutes work together in order to achieve their own value target. This model follows the principle of complementary advantages 
and shared interests.

\subsection{The Three-Dimensional Innovation Space Elements}

This paper, with reference to the definition of Schumpeter that the innovation is exactly building a production function and aimed at potential gain, divided the factors affecting construction enterprise technology innovation mode selection into three categories such as internal innovation resources (X), external innovative resources $(\mathrm{Y})$ and Innovative technology features $(\mathrm{Z})$. Technology innovation model is a function $F_{i}(\mathrm{X}, \mathrm{Y}, \mathrm{Z})$ integrating these three factors where $i$ represent different categories. Correspondingly, the innovation performance (W) can be expressed as $\mathrm{W}=F_{i}(\mathrm{X}, \mathrm{Y}, \mathrm{Z})$. Thus it can be seen, when $\mathrm{X}, \mathrm{Y}$ and $\mathrm{Z}$ is established the innovation performance of building enterprise depends on the choice of technological innovation mode $F_{i}$.

According to the different connotation and characteristics of innovation model, we can establish the corresponding relation between construction enterprise technology innovation mode and three-dimensional innovation elements, as shown in Table 1.

\subsection{Innovation Index System of Pattern Recognition for Large and Medium-Sized Construction Enterprise Technology}

The index system of technology innovation mode for large and medium-sized construction enterprise covers a wide range of indicators. In order to make these indicators comparable, this paper will take example by Gao N. N. [17], Wang B. Y. [12], Chen F. [18], Wang M. J. [19], Jing Q. [20], Xiong W. [19], Zhan Y. [20], $\mathrm{Fu}$ J. C. [21] and construct the selection index system for large and mediumsized construction enterprise technology innovation mode based on the source of technology and its complexity. As a result, the following indexes are filtrated as a basis to identify different innovation model. Namely, internal innovation resources $(\mathrm{X})$, external innovative resources $(\mathrm{Y})$, technical characteristics $(\mathrm{Z})$.

As shown in Table 2, the index system of technology innovation mode for large and medium-sized construction enterprise is built.

After every index was obtained, according to the following methods, we can identify the current technology innovation model enterprise employed:

Table 1. The corresponding relation between construction enterprise technology innovation mode and three-dimensional innovation elements.

\begin{tabular}{cccc}
\hline $\begin{array}{c}\text { Innovation } \\
\text { mode }\end{array}$ & $\begin{array}{c}\text { Internal } \\
\text { innovation resources (X) }\end{array}$ & $\begin{array}{c}\text { External } \\
\text { innovation resources (Y) }\end{array}$ & $\begin{array}{c}\text { Features of } \\
\text { innovative (Z) }\end{array}$ \\
\hline$F_{1}$ & Rich & Insufficient & Simple \\
$F_{2}$ & Rich & Insufficient & Ordinary \\
$F_{3}$ & Rich & Ordinary & Complex \\
$F_{4}$ & Insufficient & Rich & Simple \\
$F_{5}$ & Ordinary & Ordinary & Ordinary \\
$F_{6}$ & Ordinary & Rich & Ordinary \\
\hline
\end{tabular}


Table 2. The index system of technology innovation mode for large and medium-sized construction enterprise.

\begin{tabular}{|c|c|c|}
\hline $\begin{array}{c}\text { Technology } \\
\text { innovation mode }\end{array}$ & The evaluation index & Weight \\
\hline \multirow{5}{*}{$F_{1}$} & Investment amount of self-directed scientific research project $\left(F_{11}\right)$ & $\beta_{11}$ \\
\hline & Internal spending of $\mathrm{R} \& \mathrm{D}\left(F_{12}\right)$ & $\beta_{12}$ \\
\hline & Take the national or provincial science and technology plan projects $\left(F_{13}\right)$ & $\beta_{13}$ \\
\hline & International partnership $\left(F_{14}\right)$ & $\beta_{14}$ \\
\hline & Patent total $\left(F_{15}\right)$ & $\beta_{15}$ \\
\hline \multirow{3}{*}{$F_{2}$} & The number of introducing scientific and technological achievements $\left(F_{21}\right)$ & $\beta_{21}$ \\
\hline & Investment amount of self-directed scientific research project $\left(F_{22}\right)$ & $\beta_{22}$ \\
\hline & Internal spending of $\mathrm{R} \& \mathrm{D}\left(F_{23}\right)$ & $\beta_{23}$ \\
\hline \multirow{5}{*}{$F_{3}$} & The accumulative amount of the technology import fee and technical reform fee (Ten thousand yuan) $\left(F_{31}\right)$ & $\beta_{31}$ \\
\hline & Equipment purchase cost (Ten thousand yuan) $\left(F_{32}\right)$ & $\beta_{32}$ \\
\hline & The cost of digestion and absorption for new technology (Ten thousand yuan) $\left(F_{33}\right)$ & $\beta_{33}$ \\
\hline & The accumulative number of introducing scientific and technological achievements $\left(F_{34}\right)$ & $\beta_{34}$ \\
\hline & $\begin{array}{l}\text { The accumulative number of another innovation for introducing scientific } \\
\text { and technological achievements }\left(F_{35}\right)\end{array}$ & $\beta_{35}$ \\
\hline \multirow{4}{*}{$F_{4}$} & Equipment purchase cost (Ten thousand yuan) $\left(F_{41}\right)$ & $\beta_{41}$ \\
\hline & The cost of digestion and absorption for new technology (Ten thousand yuan) $\left(F_{42}\right)$ & $\beta_{42}$ \\
\hline & Internal spending of $\mathrm{R} \& \mathrm{D}\left(F_{43}\right)$ & $\beta_{43}$ \\
\hline & The accumulative amount of the technology import fee and technical reform fee $\left(F_{44}\right)$ & $\beta_{44}$ \\
\hline \multirow{8}{*}{$F_{5}$} & The proportion of foreign cooperation projects of all development project $\left(F_{51}\right)$ & $B_{51}$ \\
\hline & The accumulative amount of scientific research funds cooperated with other enterprises $\left(F_{52}\right)$ & $\beta_{52}$ \\
\hline & Accumulative amount of technology research project cooperated with domestic enterprise $\left(F_{53}\right)$ & $\beta_{53}$ \\
\hline & Accumulative amount of Promotion project cooperated with domestic enterprise $\left(F_{54}\right)$ & $\beta_{54}$ \\
\hline & Take the national or provincial science and technology plan projects $\left(F_{55}\right)$ & $\beta_{55}$ \\
\hline & National science and technology major projects $\left(F_{56}\right)$ & $\beta_{56}$ \\
\hline & International partnership program $\left(F_{57}\right)$ & $\beta_{57}$ \\
\hline & Provincial science and technology plan $\left(F_{58}\right)$ & $\beta_{58}$ \\
\hline \multirow{11}{*}{$F_{6}$} & $\begin{array}{l}\text { research and development funds entrusting universities and scientific research institutes to carry out the } \\
\text { science and technology research }\left(F_{61}\right)\end{array}$ & $\beta_{61}$ \\
\hline & The number of industry-university-research cooperation project $\left(F_{62}\right)$ & $\beta_{62}$ \\
\hline & $\begin{array}{l}\text { The funds of industry-university-research cooperation project account for the proportion of science and } \\
\text { technology research and development spending }\left(F_{63}\right)\end{array}$ & $\beta_{63}$ \\
\hline & Accumulative amount of scientific research project cooperated with colleges and universities $\left(F_{64}\right)$ & $\beta_{64}$ \\
\hline & $\begin{array}{l}\text { Accumulative amount of science and technology research entrusting universities and scientific research } \\
\text { institutes to carry out }\left(F_{65}\right)\end{array}$ & $\beta_{65}$ \\
\hline & Accumulative amount of Promoting scientific research findings at colleges and universities $\left(F_{66}\right)$ & $\beta_{66}$ \\
\hline & $\begin{array}{l}\text { Accumulative amount of successful application on projects cooperated with universities, } \\
\text { scientific research institutes }\left(F_{67}\right)\end{array}$ & $\beta_{67}$ \\
\hline & Take the national or provincial science and technology plan projects $\left(F_{68}\right)$ & $\beta_{68}$ \\
\hline & National science and technology major projects $\left(F_{69}\right)$ & $\beta_{69}$ \\
\hline & National science and technology major projects $\left(F_{610}\right)$ & $\beta_{610}$ \\
\hline & Provincial science and technology plan $\left(F_{611}\right)$ & $\beta_{611}$ \\
\hline
\end{tabular}


1) Independent innovation: $F_{1}=\sum_{i=1}^{N i} \beta_{1 i} * F_{1 i}(N i=5)$.

2) Integrated innovation mode: $F_{2}=\sum_{i=1}^{N j} \beta_{1 j} * F_{1 j}(N j=3)$;

3) Innovation model via introduction, digestion and absorption:

$F_{3}=\sum_{i=1}^{N k} \beta_{1 k} * F_{1 k}(N k=5)$;

4) Imitation innovation: ' $F_{4}=\sum_{i=1}^{N l} \beta_{1 l} * F_{1 l}(N l=4)$;

5) Cooperative innovation: $F_{5}=\sum_{i=m}^{N m} \beta_{1 m} * F_{1 m}(N m=8)$;

6) Industry-university-research cooperation innovation mode:

$F_{6}=\sum_{i=1}^{N q} \beta_{1 q} * F_{1 q}(N q=11)$

$\beta_{i j}$ denotes for index weigh of different innovation patterns, as above six kind of modes are independent of each other,

$\sum_{i=1}^{N i} \beta_{1 i}=\sum_{i=1}^{N j} \beta_{1 j}=\sum_{i=1}^{N k} \beta_{1 k}=\sum_{i=1}^{N l} \beta_{1 l}=\sum_{i=m}^{N m} \beta_{1 m}=\sum_{i=1}^{N q} \beta_{1 q}=1$. After we got the value of $F_{1}, F_{2}, F_{3}, F_{4}, F_{5}$ and $F_{6}$, the innovation model corresponding the $\max \left\{F_{1}, F_{2}, \cdots, F_{6}\right\}$ was the enterprise' current technology innovation model. It should be pointed out that a current innovation mode enterprise adopt is not necessarily the most suitable for the enterprise and we need to establish the selection model of technological innovation mode for the sake of finding the optimal technological innovation mode for given enterprise.

\section{Innovation Mode Selection for Large and Medium-Sized Construction Enterprise}

\subsection{The Construction of a $3 \mathrm{~d}$ Model}

Similar to Table 1, X, Y, Z is also composed of several factors, by means of designing the corresponding evaluation index system and calculation methods, its corresponding value can be obtained. For convenience, this paper introduces the concept of "strength", with XT, YT, ZT said resources strength of internal innovation, resources strength of external innovation and strength of technical characteristics, respectively and divided into three levels 1, 2, 3, namely, (XT, YT, $\mathrm{ZT} \in\{1,2,3\})$. The value of XT, YT and ZT shows the performance of the internal innovation resources, external innovation resources and technology characteristics. For example, XT = 1 indicate that internal innovation resources of enterprise are insufficient, $\mathrm{YT}=2$ manifest the external innovation resources of are general and $\mathrm{ZT}=3$ show research and development technology is relatively complex. In general, if the value of combination (XT, YT, ZT) composed of XT, YT, ZT change, the choice of enterprise technology innovation mode will change. Different (XT, YT, ZT) value will produce 27 kinds of combination. Therefore, the three dimensional space for enterprise technology innovation mode selection can be built as shown in Figure 1, where each small cube (XT, $\mathrm{YT}, \mathrm{ZT})$ represents a combination (XT, YT, ZT), namely, $\left(\mathrm{XT}_{\mathrm{n}}, \mathrm{YT}_{\mathrm{n}}, \mathrm{ZT}_{\mathrm{n}}\right)(\mathrm{n}=$ 27).

\subsection{The Optimal Selection of Technological Innovation Mode}

In order to visually describe every little cube how to corresponding with technological innovation model, we may list each set of values of (XTn, YTn, ZTn). At the same time, we established the relation between each cube and technology 


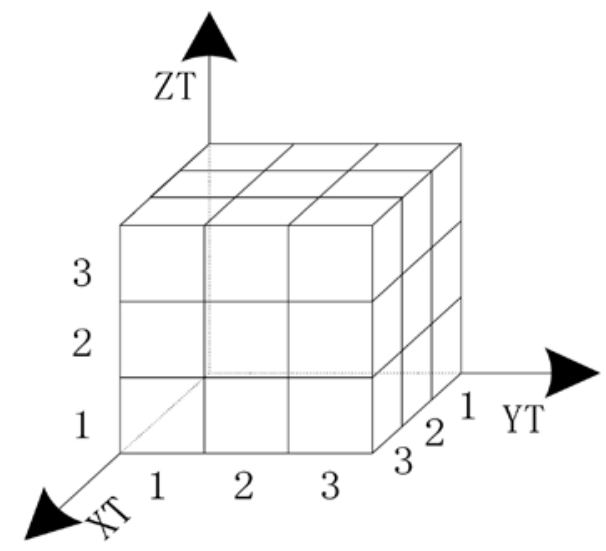

Figure 1. Three-dimensional space model for enterprise technology innovation mode selection.

innovation model by means of qualitative analysis method and the opinions of the experts, as shown in Table 3.

As shown in Table 4, six different colors small cube are used respectively to identified 6 kinds of different technological innovation models and their position within the three-dimensional space is showed in Figure 2.

\section{Innovation Mode Selection Method}

1) According to the investigation result of enterprise technology innovation index, we can separately calculated the $\mathrm{X}, \mathrm{Y}$ and $\mathrm{Z}$ of enterprise and get the corresponding combination $\left(\mathrm{XT}_{\mathrm{k}}, \mathrm{YT}_{\mathrm{k}}, \mathrm{ZT}_{\mathrm{k}}\right)$.

2) Find corresponding cube of $\left(\mathrm{XT}_{\mathrm{k}}, \mathrm{YT}_{\mathrm{k}}, \mathrm{ZT}_{\mathrm{k}}\right)$ in the coordinate system.

3) Compare the current technology innovation model such as $F_{0}$ with the best technology innovation mode $F_{1}$, if the same, so $F_{0}$ is the best mode. Otherwise, the current technology innovation model should be adjusted for optimal innovation model $F_{i}$ with reference to Table 3.

4) The construction of index system about internal enterprise resource $X$, external resources $\mathrm{Y}$, technical feature $\mathrm{Z}$ and innovation benefits $\mathrm{W}$ is similar to technology innovation model $F$ and the coefficient of each index can get by consulting experts. The calculation method is as follows:

Internal innovation resources $\mathrm{X}$ is expressed as $\mathrm{X}=\mathrm{aX}_{1}+\mathrm{bX}_{2}+\mathrm{cX_{3 }}+\mathrm{dX}_{4}$, where the coefficient $\mathrm{a}=0.4, \mathrm{~b}=0.3, \mathrm{c}=0.2, \mathrm{~d}=0.1$ and $\mathrm{X}_{1}, \mathrm{X}_{2}, \mathrm{X}_{3}, \mathrm{X}_{4}$ respectively denotes innovation motivation, innovation investment, research and development ability and management ability.

External innovation resources $\mathrm{Y}$ is expressed as $\mathrm{Y}=\mathrm{eY}_{1}+\mathrm{fY}_{2}$, where the coefficient $e=0.5, f=0.5$ and $Y_{1}, Y_{2}$ is the policy environment and industry environment, respectively.

Technical characteristics $\mathrm{Z}$ is expressed as $\mathrm{Z}=\mathrm{gZ}_{1}+\mathrm{h} \mathrm{Z}_{2}$, where the coefficient $\mathrm{g}=0.4, \mathrm{~h}=0.6$ and $\mathrm{Z}_{1}, \mathrm{Z}_{2}$ is technology complexity and technology silent feature, respectively.

Technological innovation efficiency $\mathrm{W}$ is expressed as $\mathrm{W}=\mathrm{aW}_{1}+\mathrm{bW}_{2}$, where 
Table 3. The optimal selection of technological innovation mode.

\begin{tabular}{|c|c|c|c|c|c|}
\hline$\left(\mathrm{XT}_{\mathrm{i}}, \mathrm{YT}_{\mathrm{i}}, \mathrm{ZT}_{\mathrm{i}}\right)$ & Innovation mode & $\left(\mathrm{XT}_{\mathrm{i}}, \mathrm{YT}_{\mathrm{i}}, \mathrm{ZT}_{\mathrm{i}}\right)$ & Innovation mode & $\left(\mathrm{XT}_{\mathrm{i}}, \mathrm{YT}_{\mathrm{i}}, \mathrm{ZT}_{\mathrm{i}}\right)$ & Innovation mode \\
\hline$(1,1,1)$ & $\begin{array}{l}\text { Imitation innovation } \\
\qquad\left(F_{4}\right)\end{array}$ & $(2,1,1)$ & $\begin{array}{l}\text { Independent innovation } \\
\qquad\left(F_{1}\right)\end{array}$ & $(3,1,1)$ & Independent innovation $\left(F_{1}\right)$ \\
\hline$(1,1,2)$ & $\begin{array}{l}\text { Imitation innovation } \\
\qquad\left(F_{4}\right)\end{array}$ & $(2,1,2)$ & $\begin{array}{c}\text { Industry-university-research } \\
\text { cooperation innovation } \\
\text { mode }\left(F_{6}\right)\end{array}$ & $(3,1,2)$ & $\begin{array}{l}\text { Independent innovation } \\
\qquad\left(F_{1}\right)\end{array}$ \\
\hline$(1,1,3)$ & $\begin{array}{l}\text { Imitation innovation } \\
\qquad\left(F_{4}\right)\end{array}$ & $(2,1,3)$ & $\begin{array}{l}\text { Industry-university-research } \\
\text { cooperation innovation } \\
\text { mode }\left(F_{6}\right)\end{array}$ & $(3,1,3)$ & $\begin{array}{c}\text { Industry-university-research } \\
\text { cooperation innovation mode } \\
\left(F_{6}\right)\end{array}$ \\
\hline$(1,2,1)$ & $\begin{array}{l}\text { Imitation innovation } \\
\qquad\left(F_{4}\right)\end{array}$ & $(2,2,1)$ & $\begin{array}{l}\text { Independent innovation } \\
\qquad\left(F_{1}\right)\end{array}$ & $(3,2,1)$ & $\begin{array}{l}\text { Independent innovation } \\
\qquad\left(F_{1}\right)\end{array}$ \\
\hline$(1,2,2)$ & $\begin{array}{l}\text { Imitation innovation } \\
\qquad\left(F_{4}\right)\end{array}$ & $(2,2,2)$ & $\begin{array}{l}\text { innovation model via } \\
\text { introduction, digestion and } \\
\text { absorption }\left(F_{3}\right)\end{array}$ & $(3,2,2)$ & $\begin{array}{l}\text { innovation model via } \\
\text { introduction ,digestion } \\
\text { and absorption }\left(F_{3}\right)\end{array}$ \\
\hline$(1,2,3)$ & Cooperative innovation $\left(F_{5}\right)$ & $(2,2,3)$ & $\begin{array}{l}\text { innovation model via } \\
\text { introduction ,digestion } \\
\text { and absorption }\left(F_{3}\right)\end{array}$ & $(3,2,3)$ & $\begin{array}{c}\text { innovation model via } \\
\text { introduction ,digestion and } \\
\text { absorption }\left(F_{3}\right)\end{array}$ \\
\hline$(1,3,1)$ & Cooperative innovation $\left(F_{5}\right)$ & $(2,3,1)$ & $\begin{array}{l}\text { Cooperative innovation } \\
\qquad\left(F_{5}\right)\end{array}$ & $(3,3,1)$ & $\begin{array}{l}\text { Integrated innovation mode } \\
\qquad\left(F_{2}\right)\end{array}$ \\
\hline$(1,3,2)$ & $\begin{array}{l}\text { Industry-university-research } \\
\text { cooperation innovation mode }\left(F_{6}\right)\end{array}$ & $(2,3,2)$ & $\begin{array}{l}\text { Cooperative innovation } \\
\qquad\left(F_{5}\right)\end{array}$ & $(3,3,2)$ & $\begin{array}{l}\text { Integrated innovation mode } \\
\qquad\left(F_{2}\right)\end{array}$ \\
\hline$(1,3,3)$ & $\begin{array}{l}\text { Industry-university-research } \\
\text { cooperation innovation mode } \\
\qquad\left(F_{6}\right)\end{array}$ & $(2,3,3)$ & $\begin{array}{l}\text { Integrated innovation mode } \\
\qquad\left(F_{2}\right)\end{array}$ & $(3,3,3)$ & $\begin{array}{l}\text { Integrated innovation mode } \\
\qquad\left(F_{2}\right)\end{array}$ \\
\hline
\end{tabular}

Table 4. The cube of different innovation mode.

\begin{tabular}{ccc} 
Innovation mode $F_{i}$ & $\begin{array}{c}\text { The color of } \\
\text { innovation model }\end{array}$ & Innovation mode $F_{i}$ \\
\hline$F_{3}$ & $F_{2}$ & $F_{5}$ \\
\hline
\end{tabular}

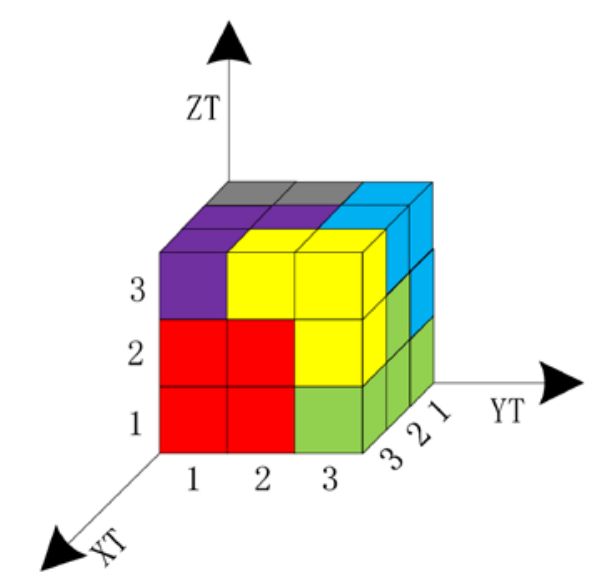

Figure 2. Three-dimensional coordinate system of technical pattern. 
$\mathrm{a}=0.8, \mathrm{~b}=0.2$ and $\mathrm{W}_{1}, \mathrm{~W}_{2}$ is economic benefits and social benefits, respectively.

\section{Conclusions}

The choice of technology innovation mode will influence enterprise innovation performance, but related research is not much and this article provides a method of choosing technology innovation model for large and medium-sized construction. Unlike most of the related research, this paper adopts quantitative research methods and establishes a multidimensional and quantitative enterprise technology innovation mode selection model for large and medium-sized construction in China on the basis of reasonable definition of enterprise technology innovation mode and its dimensions. That is to say, firstly, we establish an index system of technology innovation model for large and medium-sized construction enterprise, through which we can calculate and recognize the enterprise technology innovation mode adopted in the current. Secondly, the factors of three dimensional space belong to the enterprise technology innovation mode selection (F) are divided into internal innovation resources (X), external innovation resources $(\mathrm{Y})$ and technical characteristics $(\mathrm{Z})$, and then we establish the three-dimensional space model of enterprise technology innovation model. In the end, find the position of innovation model used by an enterprise at present in the space, according to Table 4, then we can get the corresponding optimal model.

The method provided in this paper is also appropriate for other industries, on the condition that the innovation model type is identified and selection index changes. Therefore, this study has widely application value. But this paper also has some limitations: first, there are many classification methods on the technology innovation mode, but this paper only selects the one which is presented by $\mathrm{Fu} \mathrm{J}$. J, and whether this classification method is suitable for construction enterprise or not is not explicitly discussed in this paper. Furthermore, from the industry level, the construction enterprise technology innovation has its particularity and how the characteristics of construction industry influence the choice of enterprise technology innovation mode remains to be further research.

\section{References}

[1] Chen, Y.M. and Qin, J.P. (2007) The Choice of Enterprise Technology Innovation Mode. Modern Management Science, No. 7, 46-51.

[2] Zhong, W.J., Mei, S.E. and Xie, Y.Y. (2009) An Analysis of Production-Study-Research Cooperation Technological Innovation Mode. China Soft Science, No. 8, 7481.

[3] Lin, C.P., Zhang, Z.G. and Tian, S. (2009) The Secondary Innovation: Introduction and Absorption Based on Matching the Technology Capacity and Technology Innovation Model. China Science and Technology Forum, No. 9, 16-18.

[4] Lv, J.H. (2005) A Research on Core Competitive of High and New Technology Enterprises. Ph.D. Thesis, China Northeast Forestry University, Harbin, 68-79.

[5] Han, Z., Fan, H.M. and Feng, L. (2009) A Research on the Dynamic Gradient Mode of Technology Innovation for Small and Medium-Sized High-Tech Enterprises in 
China. Science and Technology Management Research, No. 9, 72-75.

[6] Wen, K.Y. (2013) A Research on Construction Enterprise Technology Innovation. The Chinese and Foreign Construction, No. 6, 109-110.

[7] Fu, J.J. and Jiang, Y.F. (1992) Technological Innovation-The Development of Chinese Enterprises. Enterprise Management Publishing, Peking, 16-24.

[8] An, Y.N. (2013) A Research on Technology Innovation Mode Selection for China's Large Enterprise. Ph.D. Thesis, Harbin Engineering University, Harbin, 16-35.

[9] Chen, Y.X. and Tu, W.J. (2012) Research on Enterprise Technology Innovation Mode Selection and Its Evolution Based on the Technical Ability. Scientific and Technological Progress and Countermeasures, No. 7, 47-53.

[10] Guo, C.D. (2013) Research on Enterprise Technology Innovation Mode Selection and Development Path. Ph.D. Thesis, Beijing Institute of Technology, 124-139.

[11] Zeng, H. and Yang, P. (2010) Research on Construction Enterprise Technology Innovation Mechanism and Model Based on The Theory of Social Capital. Building Economy, No. 4, 78-82.

[12] Wang, B.Y. (2005) Research on Technology Innovation Mode Selection Model for High and New Technology Enterprise. Journal of Xi'an University of Electronic Science and Technology, No. 3, 114-118.

[13] Chen, Y.M. (2015) The Selection of Enterprise Technology Innovation Mode. Economic Manager, No. 11, 65-70.

[14] Xia, C.Y. (1997) China's Technology Innovation Mode. China Science and Technology Industry, No. 07, 78-83.

[15] Tang, Q.Q., and Li, H.W. (2011) The Innovation Pattern Choice of Enterprise in China. Contemporary Economy \& Management, No. 12, 36-39.

[16] Wang, H.G. (2004) The Analysis and Choice of Technology Innovation Mode. Technological Innovation \& Management, No. 1, 68-72.

[17] Gao, N.N. (2008) The Study of the Patterns of Building Enterprise Technology Innovation. Ph.D. Thesis, Harbin Institute of Technology, Harbin, 15-28.

[18] Chen, F. and Wang, M.J. (2009) The Evaluation on Building Enterprise Independent Innovation Ability. Science and Technology Management Research, No. 2, 98-103.

[19] Xiong, W. (2012) A research on Technology Innovation Ability Evaluation System for Large and Medium-Sized Construction Enterprise. Ph.D. Thesis, Wuhan University of Science and Technology, Wuhan, 26-39.

[20] Zhan, Y. (2014) A Research on Factors that Affect Construction Enterprise Independent Innovation Ability and Its Evaluation. Ph.D. Thesis, Qingdao University of Science and Technology, Qingdao, 19-46.

[21] Fu, J.C. (2013) A Research on Production-Study-Research Cooperation Mechanism and Performance Evaluation. Ph.D. Thesis, China University of Geosciences, Wuhan, 58-69. 
Submit or recommend next manuscript to SCIRP and we will provide best service for you:

Accepting pre-submission inquiries through Email, Facebook, LinkedIn, Twitter, etc. A wide selection of journals (inclusive of 9 subjects, more than 200 journals)

Providing 24-hour high-quality service

User-friendly online submission system

Fair and swift peer-review system

Efficient typesetting and proofreading procedure

Display of the result of downloads and visits, as well as the number of cited articles Maximum dissemination of your research work

Submit your manuscript at: http://papersubmission.scirp.org/

Or contact ti@scirp.org 